\title{
Christine "la mujer desencarnada" y el papel de las metáforas corporales en el conocimiento de la realidad
}

\author{
Christine "the Disembodied Lady" and the role of body \\ metaphors in the knowledge of reality
}

MARIAN PÉREZ BERNAL*

\begin{abstract}
Resumen: Christine es una paciente tratada por el neurólogo Oliver Sacks y cuyo caso aparece en El hombre que confundió a su mujer con un sombrero. Christine padece una extraña enfermedad que hace que su cuerpo deje de obedecerla. Se siente extraña, se siente "desencarnada". Este artículo se centra en cómo la mente se halla encarnada. La semántica cognitiva subraya que pensamiento y cuerpo no son entidades separadas. El cuerpo ejerce influencia en el conocimiento y en el lenguaje en un nivel muy básico. Nuestro cuerpo está detrás de muchas de las metáforas que empleamos de forma cotidiana.

Palabras claves: metáfora, expresión metafórica, cuerpo, teoría cognitiva, conocimiento,
\end{abstract}

\begin{abstract}
Christine is a woman patient treated by the neurologist Oliver Sacks. Her case appears in the The Man Who Mistook His Wife for a Hat. Christina suffered from a strange illness. One day her body ceased to obey her. She feels strange, "disembodied". This paper concentrates on this topic: the mind as something inherently embodied. Cognitive semantics maintains that body and thought are not separate entities. The body is seen as exerting its influence on language and knowledge at a more basic level now. Embodied metaphors are very prevalent in everyday talk, even if the bodily origin is often not easily evident.
\end{abstract}

Key words: Metaphor, Metaphorical expression, Body, Cognitive Theory, Knowledge

En su obra El hombre que confundió a su mujer con un sombrero, el neurólogo Oliver Sacks nos cuenta el caso de la joven Christina. ¿Qué le pasó a esta mujer? Christina sufrió una extraña enfermedad. Un buen día y sin que se supiese por qué su cuerpo comenzó a no responderle. No podía mantenerse en pie, no podía sostener nada en las manos y apenas podía mantenerse incorporada. Solo si fijaba su visión sobre sus manos conseguía moverlas según su voluntad e igual le sucedía con el resto del cuerpo. Ante las preguntas de los médicos su única explicación era: "No siento el cuerpo. Me siento rara, desencarnada".

Fecha de recepción: 09/06/2016. Fecha de aceptación: 20/07/2016.

* Universidad Pablo de Olavide. Profesora Contratado Doctor. Filosofía del Lenguaje e Historia del pensamiento feminista. Correo: mdperber@upo.es. Artículos: "Metáfora frente a analogía: Del pudín de pasas al fuego diabólico", Thémata. Revista de Filosofía, 2007, 38, ISSN: 0210-8365, pp. 201-211; “The Projection of Contexts: An alternative to George Lakoff and Mark Turner's Approach to Poetic Metaphors", ES. Revista de Filología Inglesa, 33, Universidad de Valladolid, 2012, pp. 235-251. 
Tras largas pruebas los médicos descubren un déficit propioceptivo casi total, lo que hacía que, aunque los lóbulos parietales funcionaban a la perfección, no podían funcionar porque no tenían nada con qué funcionar. Se trataba de una polineuritis de tipo muy extraño que le había hecho perder por completo la propiocepción. Solo el sentido de la visión podía ahora suplir el hueco provocado por esta enfermedad que había dejado al cuerpo ciego. Según nos cuenta Oliver Sacks las cosas fueron mejorando y poco a poco la retroacción inconsciente de la visión fue sustituyendo a la propiocepción, sin embargo hubo muchas horas bajas y muchas quejas ante la situación.

Traemos a colación la extraña enfermedad de Christina porque nos recuerda la importancia de la corporalidad en nuestra vida y también en el modo como conocemos la realidad. En principio parece evidente que conocemos con nuestro cuerpo y gracias a nuestro cuerpo y desde pequeñitos se nos enseñan cuáles son los sentidos fundamentales y de qué nos informan la vista, de qué el tacto, de qué el olfato, etc. Sin embargo, a pesar de la evidencia de esta realidad, durante siglos gran parte de la filosofía ha vivido totalmente de espaldas a esta cuestión y sin prestarle la atención que merece.

La escisión cartesiana entre la res cogitans y res extensa -sin duda apoyada por toda una tradición cultural coincidente- desgraciadamente tuvo una inmensa fortuna y todavía somos en cierto modo herederos de esta visión quebrada de la realidad. Parece que solo hay dos sentidos del vocablo existir: o se existe como cosa o se existe como conciencia y entre ambas formas de existencia parece que no hay posible comunicación. Puedo tener absoluta certeza de mi existencia como "cosa que piensa", ahora bien, eso no me permite decir nada acerca de mi corporalidad (Descartes 1999 (1637):93). Mi existencia como cosa que piensa se me muestra como una verdad clara y distinta mientras que el cuerpo queda atrapado en el horizonte brumoso de lo dudable. Lo que conocemos de forma clara y distinta es así la estructura de nuestra mente y no nuestra corporalidad. Así pues mente y conocimiento, por un lado, cuerpo y percepción, por otro, se presentan como realidades independientes que sólo entrarían en comunión gracias a una misteriosa glándula pineal.

Nos encontramos ante el reiterado problema del puente presente ya desde el escéptico Pirrón: ¿cómo puedo saber que los objetos que están fuera coinciden con las impresiones o las ideas que están dentro? ¿Cómo puedo saltar de lo subjetivo a lo objetivo? ¿Es posible ir más allá del teatro cartesiano? Solo con la ayuda de Dios -y lo digo literalmente, en este caso no se trata de una metáfora- fue Descartes capaz de superar un abismo que él hizo infranqueable.

Romper con esta dicotomía es básico y sin embargo han sido necesario el paso de mucho tiempo para que esto se nos hiciera evidente. Desde el ámbito de la neurobiología tanto Damasio con "el error de Descartes" como Llinás con "el mito del yo" están apelando a la necesidad de superar este dualismo para poder abordar la naturaleza neurobiológica de la mente (Damasio 1996, 230; Llinás, 2003, XVI). Es preciso enfrentarnos a la cuestión desde una perspectiva monista donde el cerebro y la mente son eventos inseparables. Los procesos mentales son procesos cerebrales. Tenemos que liberarnos del "error de Descartes" que según Damasio tanto daño nos ha hecho. ¿Cuál fue según este neurobiólogo la terrible equivocación de Descartes? Escuchemos sus palabras:

“(...) la separación abismal entre el cuerpo y la mente, entre el material del que está hecho el cuerpo, medible, dimensionado, operado mecánicamente, infinitamente 
divisible, por un lado, y la esencia de la mente, que no se puede medir, no tiene dimensiones, es asimétrica, no divisible; la sugerencia de que el razonamiento, el juicio moral y el sufrimiento que proviene del dolor físico o de la conmoción emocional pueden existir separados del cuerpo. Más específicamente: que las operaciones más refinadas de la mente están separadas de la estructura y funcionamiento de un organismo biológico" (Damasio, 1996, 230)

Entre mente y realidad se abre a partir de Descartes una brecha que ha pesado sobre toda la historia de la filosofía posterior (Johnson, 1991, 32) (Lakoff \& Johnson, 1999, 94). En realidad superar -si es que está superado- el dualismo cartesiano no ha sido tarea fácil. Nuestra ciencia y nuestra filosofía -dirá Merleau-Ponty- son dos continuaciones fieles e infieles del cartesianismo, dos monstruos nacidos de su desmembramiento (Merleau-Ponty, 1977 (1961), 43). Puede ser que res cogitans, res extensa o glándula pineal suene ya, es cierto, a caduco, sin embargo un planteamiento similar sigue estando vigente aunque hoy se empleen metáforas bien distintas. Tras metáforas que resultan muy actuales y modernas resuenan ecos del planteamiento cartesiano. Estoy pensando, por ejemplo, en la metáfora que presenta al cerebro como el hardware y a la mente como el software. Así los procesos cognitivos se conciben como análogos al programa y a las funciones software del ordenador, mientras que el cerebro sería análogo al hardware del sistema. Esta metáfora, según Llinás, resulta totalmente inadecuada porque olvida que la mente coincide con los estados funcionales del cerebro: "el hardware y el software se entrelazan en unidades funcionales, que no son otra cosa que neuronas" (Llinás, 2003, 3).

Así pues, frente a los planteamientos dualistas, se trata de recuperar el cuerpo en estrecha comunión con la mente. Nos guste o no hay que mirar hacia el cerebro para entender el dolor y la felicidad. Christina sabe lo que supone estar desencarnada y por eso, seguramente, nunca hubiera aceptado el planteamiento cartesiano, nosotros no, quizá por eso durante tanto siglos hemos sido capaces de repetir y asumir esta escisión tan artificial. La presencia del cuerpo es tan familiar que ni siquiera le prestamos atención pero eso no significa que no sea fundamental para entender cómo captamos y pensamos la realidad. Quizás, la propia familiaridad del cuerpo impide que nos demos cuenta de su presencia. Sentimos el cuerpo como propio y por eso mismo no nos paramos a pensar en él salvo cuando se convierte en problema, tal y como le sucedió a Christina.

Los descubrimientos realizados en los últimos años en el ámbito de la neurociencia permiten que se replantee la relación entre la actividad mental y las estructuras fisiológicas y anatómicas. Desde hace unos años, han aparecido teorías nuevas que subrayan que el significado de la realidad es atribuido por un cerebro que se halla dentro de un cuerpo y que está mediatizado de diversas formas por ese cuerpo. La lingüística cognitiva aparece con una fuerza enorme en este escenario para afirmar la influencia de lo corporal y para rescatar al cuerpo del olvido y esto es posible gracias al rico florecimiento de las ciencias del cerebro. Nuestra posición vertical, el hecho de tener dos manos, dos piernas y una determinada forma de visión influyen en la forma cómo captamos la realidad y en la manera cómo nos referimos a ella ${ }^{1}$.

1 Llinás recuerda la conocida hipótesis de que los vertebrados no son más que crustáceos volteados hacia fuera. Mientras que los crustáceos son exoesqueléticos nosotros somos endoesqueléticos y esto podría en parte al menos explicar nuestro escaso conocimiento acerca del funcionamiento del cerebro. Al no poder observar ni sentir su funcionamiento nuestro conocimiento del cerebro resulta indirecto (Llinás 2003:5-6). Si fuésemos crustáceos todo sería diferente y los filósofos, que lo discuten todo, muchas veces no se detienen en pensar algo tan evidente. 
En la entrevista realizada por John Brockman, hace unos años a George Lakoff este autor afirmaba que la lingüística cognitiva surge como un intento de crear una nueva lingüística compatible con las investigaciones realizadas por la ciencia cognitiva y la neurociencia. Los tres principales logros de la ciencia cognitiva, o más concretamente de la última semántica cognitiva, esto es, de la segunda generación de la ciencia cognitiva, radican en su defensa de que la mente está intrínsecamente encarnada, en que el pensamiento es en su mayor parte inconsciente y en que los conceptos abstractos son en gran parte metafóricos. No es posible, por lo tanto, mantener el dualismo cartesiano (Lakoff \& Johnson, 1999, 3-5). A partir de estos principios toda la filosofía debe ser replanteada.

No solo vivimos en nuestro cuerpo sino que también lo usamos para pensar. En relación con esto la semántica cognitiva subraya que nuestra experiencia corporal no solo contribuye a configurar nuestra visión de la realidad sino que también entendemos esta realidad gracias a la proyección de nuestros esquemas corporales. Desde la perspectiva de la semántica cognitiva existe una serie de actividades importantes que dependerían del cerebro como entidad incluida en un cuerpo sujeto a ciertas experiencias corporales con la realidad. Ninguna de estas actividades sería explicable de forma satisfactoria desde un enfoque que olvide lo corporal. Mark Turner) destaca entre estas actividades, por ejemplo, el atribuir la verticalidad arriba-abajo; el distinguir entre el interior y el exterior en un cuerpo con la piel como límite, el dividir el mundo entre objetos y acciones o el atribuir propósitos a los agentes (Turner, 1994, 93). La experiencia corporal común explicaría el que haya ciertos esquemas metafóricos comunes a culturas distintas.

En esta comunicación nos interesa, sobre todo, el primer punto: la mente está intrínsecamente encarnada. Nosotros no podemos pensar más que aquello que nuestros cerebros encarnados nos permite. El mundo no nos es dado sino que debe ser construido a partir de nuestro aparato cognitivo y en este está muy presente la corporalidad. La comprensión del significado de un objeto supone reconstruir por medio de una especie de simulación cognitiva nuestra interacción con el objeto en términos de sus rasgos más sobresalientes. En 1987 aparece el trabajo de Mark Johnson The Body in the Mind: The Bodily Basis of Meaning, Reason and Imagination que se ha convertido ya en una obra de referencia. Johnson nos habla en esta obra de la importancia de lo corporal en lo mental y de la imposibilidad de separar ambos dominios. Las afirmaciones con las que comienza la introducción de esta obra -"Los seres humanos tenemos cuerpo" y "Nuestra racionalidad está corporeizada" (Johnson, 1991, 23) - dicen mucho de lo que va a venir después. Asumir estos planteamientos supone mirar la realidad desde una óptica nueva. Si hasta ahora hemos oído hasta la saciedad que la mente está en el cuerpo, lo que Johnson trata de explorar en su obra es el otro lado de la moneda, esto es, de qué forma "el cuerpo está en la mente" (Johnson, 1991, 47).

Así pues, situándose en la tradición inaugurada por Mark Johnson, George Lakoff rompe con las tesis propias de Montague, Fodor y Chomsky y en general del cognitivismo de viejo estilo, según las cuales los conceptos son abstracciones desencarnadas. Desde la perspectiva de Lakoff y Johnson la semántica clásica se dirige desde la realidad objetiva hasta los símbolos lingüísticos de forma directa sin pasar por el pensamiento humano. El cerebro se ve reducido a una máquina formal que realiza sólo la computación de una serie de símbolos. Los procesos cognitivos se reducirían a la manipulación de estos símbolos de acuerdo con un sistema de reglas. Su forma más conocida sería la utilización de un lenguaje como el 
mentalés (Fodor, 1975). En este caso el pensamiento se configura de forma totalmente libre, trascendiendo al cuerpo y a su experiencia. Esto procede de una distinción clásica que ve al cuerpo como una máquina habitada por un espíritu y donde el trabajo de la mente está totalmente desencarnado del cuerpo. Según Turner este planteamiento del significado es contradictorio con las recientes investigaciones neurobiológicas y cognitivas que sugieren que la mente humana está constreñida, estructurada y limitada por el cuerpo en el que reside y por el medio en que vive (Turner, 1994,97). Turner critica la teoría clásica al considerarla insuficiente a la hora de explicar la semántica al no tener presente que el significado es un aspecto dinámico del pensamiento.

Mientras que la teoría tradicional presenta al cuerpo y al pensamiento como dos realidades separadas, la semántica cognitiva defiende una postura opuesta. La influencia del cuerpo en el lenguaje y en el conocimiento se sitúa ahora en un nivel más básico. Ya no se trata sólo de que el sexo, la edad, la situación social o la procedencia mediatice de una forma u otra el conocimiento de la realidad y la forma como nos referimos a ellas, sino que existe algo más básico y general común a todos los sujetos. El encarnamiento humano influye en cómo pueden ser significativas las cosas, en los modos en que esos significados pueden ser desarrollados y articulados, y en la forma en que estamos capacitados para comprender y razonar sobre nuestra experiencia. No tiene sentido seguir hablando de los conceptos de la forma como lo hace la teoría clásica (Lakoff 1989:103) (Lakoff, 1994, 42). No hay una facultad racional separada e independiente de las capacidades corporales tales como la percepción y el movimiento porque nuestra capacidad racional está intrínsecamente unida a nuestro cuerpo y a nuestro cerebro. Los conceptos están conformados a partir de nuestros cuerpos y nuestros cerebros, especialmente nuestro sistema sensoriomotor (Lakoff \& Johnson, 1980) (Johnson, 1987) (Lakoff, 1989) (Lakoff \& Johnson, 1999)... A través de la metáfora, podemos emplear patrones obtenidos en la experiencia física para organizar una comprensión de tipo más abstracto (Johnson 1987:72-85). En la teoría corpórea la estructura es el producto de un proceso de construcción, a partir del núcleo significativo proporcionado por los esquemas de imágenes. Podemos decir que tras este planteamiento se está defendiendo un realismo encarnado -“embodied realism”-, esto es, nuestro conocimiento están constreñido por nuestras facultades perceptivas, nuestra estructura anatómica y por patrones de nuestra actividad neurológica ${ }^{2}$. Comprendemos la realidad gracias a la interacción con conceptos procedentes de nuestro estar encarnados (Lakoff \& Johnson, 1999, 93). Así, nuestra forma de razonar no se puede separar de nuestro carácter corporal y hablar de ella de forma trascendente solo nos puede llevar al error (Lakoff y Johnson, 1999, 4).

La noción de embodiment pretende recoger el carácter corpóreo de la cognición y del lenguaje. El experiencialismo destaca la importancia del cuerpo humano en la comprensión de los conceptos y examina en qué medida nuestros cuerpos tienen influencia sobre la manera en que pensamos. "Los hombres, tenemos cuerpos y todos tenemos una relación íntima con nuestro cuerpo" - dirá Gibbs (1996: 14) y esta relación íntima con nuestro cuerpo y la omnipresencia de las experiencias corpóreas en nuestra vida explica la posición central que ocupa el cuerpo en nuestra cognición y, por consiguiente, en el lenguaje humano. La

2 Sobre la posibilidad de conjugar sin problema "encarnamiento" y "realismo" es muy interesante la reflexión que realiza Johnson (Johnson, 1991 (1987), 291-314). 
comprensión de las metáforas se fundamentan sobre nuestra experiencia corporal (Gibbs, Costa Vila \& Francozo, 2004) La ciencia cognitiva estima que construimos nuestra realidad a partir de nuestro movimiento corpóreo, nuestra orientación en el tiempo y espacio y nuestras interacciones con otros hombres y objetos y esto se refleja en el lenguaje.

En relación con la cuestión de la verticalidad en un trabajo publicado en 2014 en la revista Metaphor and Symbol Xie y Zhang $(2014,172)$ aplican la teoría de la metáfora para explicar la forma como se interpretan expresiones religiosas y por qué se sitúa a Dios en los cielos y al demonio en las profundidades y que son comunes a tradiciones culturales muy diferentes. Tras estas expresiones metafóricas estarían las metáforas LO BUENO ES ARRIBA y LO MALO ES ABAJO.

En Philosophy in the Flesh Lakoff y Johnson proponen revisar toda la historia de la filosofía occidental teniendo presente los descubrimientos de las ciencias cognitivas. La filosofía no puede seguir dando la espalda a las investigaciones de estas ciencias que presentan los problemas filosóficos tradicionales -el tiempo, el yo...- de forma novedosa. De lo que se trata es de aplicar las herramientas de las ciencias cognitivas para entender mejor las teorías filosóficas y para valorar de forma más acertada su adecuación con la realidad. Tan importante es el cuerpo y tan cegados hemos estados a ella que estos autores consideran necesario revisar toda la historia de la filosofía occidental teniendo presente el cuerpo. Ya el título de la obra lo dice todo. Según Lakoff y Johnson las metáforas hasta ahora empleadas para hablar sobre la mente no dejan espacio para el cuerpo. Son necesarias, pues, en el ámbito de la filosofía nuevas metáforas que den cabida al cuerpo.

La publicación de Metaphors we Live by de Lakoff y Johnson en 1980 supuso un revulsivo en el análisis tradicional de la metáfora y más de treinta años después siguen estando de gran actualidad. Gracias a esta obra la metáfora escapó de su encierro en los manuales de retórica para pasar a ocupar un espacio propio en el ámbito de las teorías cognitivas. Lakoff y Johnson establecen una diferencia básica entre la metáfora y la expresión metafórica. La metáfora es un modo penetrante de comprensión mediante el cual proyectamos patrones de una espera de experiencia con el propósito de estructurar una esfera de otro tipo (Lakoff \& Johnson, 1991 (1980), 195-196). La función primaria de la metáfora es proporcionar una comprensión parcial de un tipo de experiencia en términos de otro tipo de experiencias: se proyecta un dominio sobre otro para facilitar su comprensión La metáfora nos permite acercarnos a realidades más abstractas con otras más concretas. La metáfora forma parte de nuestro sistema conceptual y sería el mapping que resulta del cruce de dos dominios; mientras que la expresión metafórica sería las diferentes expresiones que se pueden construir a partir de este mapping. "Siento que dejé escapar mi último tren" se basaría en la metáfora LA VIDA ES UN VIAJE o "Luchó por ella y al final perdió" sería otra expresión metafórica que a su vez se fundamentaría en EL AMOR ES UNA GUERRA. La metáfora aparece así como una realidad fundamental a la hora de analizar nuestro lenguaje y nuestro pensamiento ya que estructuran el sistema conceptual ordinario de nuestra cultura y se reflejan tanto en el lenguaje cotidiano como en el científico.

Nuestro cuerpo y nuestras experiencias corporales están detrás de una gran parte de las metáforas que utilizamos. Los datos experimentales apoyarían que un gran surtido de los dominios fuentes que empleamos para construir metáforas está muy influidos por la naturaleza de nuestros cuerpos, nuestras capacidades cerebrales y el medio en el que vivimos. 
Nuestra posición vertical, el hecho de tener dos manos, dos piernas y una determinada forma de visión influyen en la forma cómo captamos la realidad y en la manera como nos expresamos. Nos vamos a centrar en una metáfora muy habitual centrada en nuestra experiencia de la corporalidad.

Pensemos en expresiones como "Más vale que te calmes porque te está saliendo humo por las orejas" o "Después de ver lo que él hizo, estalló". Tras estas expresiones metafóricas que se hallaría la metáfora EL CUERPO ES UN CONTENEDOR DE EMOCIONES. Esta misma metáfora estaría tras algunas de las expresiones metafóricas que emplea Mario Vargas Llosa en La fiesta del chivo:

"Pero lo que la razón le dictaba no convencía a sus glándulas. Tuvo que dejar de vestirse, cegado. La rabia ascendía por todos los vericuetos de su cuerpo, río de lava trepando hasta su cerebro que parecía crepitar" (Vargas Llosa, 2000, 35)

"Lo que tanto temía. Su cerebro es una fragua al rojo vivo" (Vargas Llosa, 2000, 265)

“Trujillo refrenó la cólera que borboteaba en su interior" (Vargas Llosa, 2000,304)

"Pero ese humor que lo llevaba a encenderse como una antorcha cuando alguien le decía Negro y a dar puñetazos por cualquier motivo, frenó sus ascensos en el ejército" (Vargas Llosa, 2000, 307)

La metáfora convencional que asocia la cólera con el calor permite que al enfrentarnos a una expresión de este tipo se active en la memoria a largo plazo todas las realidades que se hallan asociadas con esta forma de plantear la cuestión. Se han utilizado rasgos procedentes del ámbito de lo concreto -la temperatura- para referirnos a algo más abstracto -la cóleraSegún Lakoff existe una organización conceptual que subyace a todas estas expresiones y que posee una naturaleza metafórica (Lakoff, 1987, 381-383). Igual que el termómetro es capaz de tomar la temperatura a los enfermos con una escala que está dividida en décimas de grado o con la vista podemos ver lo próxima que está a la ebullición el agua de una olla, el vocabulario del calor nos permite dar cuenta de los estados de ánimo. Los términos que se usan para las emociones están emparejados con sensaciones físicas.

Kövecses ha sido uno de los más prolíficos investigadores aplicando las teorías de Lakoff y Johnson sobre las metáforas conceptuales para explicar el mundo de los sentimientos. Según Kövecses $(1986,12)$ existe una organización conceptual coherente subyacente a todas estas expresiones y muchas de ellas son de naturaleza metafórica. Las expresiones que indican la ira en inglés americano no son una colección hecha al azar, sino que se estructuran en base a un modelo cognitivo elaborado que se encuentra implícito en la semántica de la lengua y se construyen a partir de dos metáforas básicas como serían: "LA CÓLERA ES CALOR" y "EL CUERPO ES UN CONTENEDOR DE LAS EMOCIONES" (Kövecses, 1986,14; Kövecses, 1995, 118). Esto indica que la ira no se conceptualiza como un sentimiento amorfo, sino que cuenta con una estructura cognitiva muy elaborada (Kövecses, 1986, 36). El vocabulario, las construcciones y las expresiones convencionales del lenguaje configuran algunos de los límites para la expresión y la comprensión de las emociones. Trasladamos nuestros conocimientos acerca del comportamiento de un fluido en un recipiente cerrado sobre nuestro concepto de la cólera. Estas expresiones se fundan sobre inferencias sistemáticas de patrones de correspondencia entre los dominios fuentes y los dominios meta. 
Conceptualizamos al ser humano como un contenedor y a las emociones como cierta clase de sustancia -normalmente un fluido- que corre por el interior de ese contenedor. Recordemos la teoría clásica de los humores.

Estas metáforas se fundan sobre una teoría popular que considera que los efectos psicológicos de la cólera son: incremento del calor corporal, incremento de la tensión interna, aumento de la presión sanguínea, agitación o incapacidad para una percepción adecuada de los hechos... Igual que el agua hierve en contacto con el fuego -calor-, la sangre puede hervir por acción de la ira -calor-. Nadie piensa que se produzcan burbujas en la sangre, ni que como consecuencia de la ebullición pueda realmente salirle a uno humo por las orejas, sin embargo todos entendemos perfectamente a qué se está uno refiriendo al decir "me hierve la sangre". Diversos rasgos de ambas realidades conforman una base válida para tal proyección: las dos son destructivas, las dos sufren fluctuaciones y ambas comparte el color rojizo; el rostro del encolerizado se torna rosado aproximándose al color del fuego. La identificación de la cólera con el calor se materializa sobre todo en la forma de un contenedor tapado lleno de líquido caliente. Cuanto más nos enfadamos más sube la temperatura de la cólera igual que aumenta la ebullición del líquido conforme subimos la temperatura de la hornilla. El calor creciente hace que de la olla salga humo, igual que saldrá humo de la persona muy enfadada. En los dibujos animados, por ejemplo, la cólera se suele representar haciendo salir vapor o humo de las orejas o de la cabeza de los personajes (Lakoff, 1984, 81). Al mismo tiempo el calor produce un aumento en la presión. Ante esto cabe apartar la olla del fuego haciendo que descienda la temperatura; igualmente el hombre puede tratar de apaciguar la furia interior. Ahora bien, si no se hace así, llega un momento en el que no aguantamos más y estallamos igual que el agua en ebullición acaba despegando la tapadera y escapando por los bordes. La pérdida de control consecuencia de la cólera sería similar a una explosión producida por un excesivo calor.

Estas metáforas se repiten tanto en las lenguas de origen indoeuropeo como en lenguas de otro origen. Encontramos las metáforas LA CÓLERA ES CALOR y EL CUERPO ES UN CONTENEDOR en inglés (Kövecses, 1986) (Kövecses \& Lakoff 1987), en chino (Ning Yu, 1988), en japonés (Matsuki, 1989), en húngaro (Kövecses, 1995) o en persa (Pirzard, Pazahkh \& Hayati, 201, 204). En todas estas lenguas se repite un esquema similar aunque con ciertas diferencias. En el caso del inglés las metáforas utilizadas para describir la cólera toman como dominios fundamentales el fuego y los fluidos, mientras que en el caso del chino se utiliza el fuego y el gas (Ning Yu, 1984, 50-82), en el húngaro no solo el cuerpo es visto como un recipiente lleno de líquido hirviente sino que también la cabeza puede ser el contenedor de ese líquido que hierve (Kövecses, 1995, 122), mientras que en el japonés, por el contrario, será el estómago el contenedor de la ira en ebullición (Matsuki, 1989). Aunque, como vemos, en cada una de estas lenguas se dan ciertas diferencias, nos interesan por encima de las diferencias los paralelismos que podemos hallar entre todos estos enfoques y el hecho de que esquemas metafóricos muy similares nos sirvan para referirnos a realidades de carácter más abstracto. Los lingüistas cognitivos consideran el carácter corpóreo del lenguaje como una de las razones básicas de los paralelismos entre las diferentes lenguas. En cuanto se considera el cuerpo como la base de la experiencia y, por consiguiente, de la cognición y del lenguaje, se entiende que los hombres comparten estructuras conceptuales, puesto que la semejanza entre nuestros cuerpos resulta siempre mayor que la diferencia. 
Gladys Nyarkos (2014) realiza una comparativa sobre las metáforas y las metonimias empleadas en inglés y en las lenguas akánicas -se trata de un grupo de variedades dialectales que se hablan en Ghana y Costa de Marfil-. Este análisis muestra que la forma como se expresa el miedo en inglés y en estas lenguas comparten importantes similitudes aunque también ciertas diferencias. Siguiendo le planteamiento de Kövecses, Nyarkos afirma que los paralelismos se expresan por el peso de lo corporal -común a todos los idiomas- en la forma de conceptualizar la realidad mientras que las diferencias se explicarían por las diferencias culturales, esto es, qué elemento se subraya más puede ser diferente en diferentes culturas. La forma de conceptualizar las emociones básicas sería universal porque se basan en el carácter corpóreo que tiene el conocimiento humano.

Comenzábamos citando a Oliver Sacks y su relato de la extraña enfermedad de Christina y terminaremos escuchando unas palabras de Hipócrates: “...del cerebro vienen las alegrías, el placer, la risa y el ocio, las penas, el dolor, el abatimiento y las lamentaciones" (Delgado García, 2004, 50). Hipócrates nos habla del cerebro y de su conexión con la risa y el dolor. De nuevo una visión monista que podemos y debemos rescatar del olvido 2.400 años después. El profesor Delgado García (2004) lanza un cable entre el texto de Hipócrates y el planteamiento de Damasio para decir que ambos, en último término, están apuntando a una misma realidad aunque los términos empleados hayan cambiado a lo largo del tiempo.

\section{Referencias citadas}

Brockman, John (2003), «Philosophy in the Flesh. A Talk with George Lakoff», The Third Culture, Edge 51, www.edge.org

Damasio, Antonio (1996), El error de Descartes. La emoción, la razón y el cerebro humano, Barcelona, Crítica.

Delgado García, José María (2004), «El tema de nuestro tiempo revisitado. Un ensayo sobre los mecanismos de nuestro mundo emocional», Revista de Occidente, 272, pp. 41-61.

Grady, John (2002), Reseña crítica de Philosophy in the Flesh: The Embodied Mind and its Challenge to Western Thought, G. Lakoff, M. Johnson, 1999, New York, Basic Books, publicada en Journal of Pragmatics, 34, pp. 1903-1909.

Johnson, Mark, (1991) El cuerpo en la mente, Madrid, Debate (Título original: The Body in the Mind: The Bodily Basis of Meaning, Reason and Imagination, 1987).

Kövecses, Zoltan (2003), Metaphor and emotion. Language, Culture and Body in Human Feeling, New York, Cambridge University Press.

Kövecses, Zoltan (2005), Metaphor in Culture. Universality and Variation, New York, Cambridge University Press.

Lakoff, George \& JOHNSON, Mark (1999), Philosophy in the Flesh: The Embodied Mind and its Challenge to Western Thought, New York, Basic Books.

Llinás, R (2003), El cerebro y el mito del yo, Barcelona, Belacqva.

Nyarko Ansah, Gladys (2014), «Culture in Embodied Cognition: Metahorical/ Metonymic Conceptualizations of FEAR in Akan and English», Metaphor and Symbol, 29, pp. 44-58.

Pirzad Mashak, Shahrzad et.al. (2012), «A Comparative Study of Basic Emotion Conceptual Metaphors in English and Persian Literary Texts», International Educational Studies, vol. 5, no 1 , pp. 200-207. 
Ruíz de Mendonza Ibáñez, Francisco José y Pérez Hernández, Lorena (2011), «The Contemporary Theory of Metaphor: Myths, Developments and Challenges», Metaphor and Symbol, 26, pp. 161-185.

Sacks, Oliver (1991), El hombre que confundió a su mujer con un sombrero, Barcelona, Muchnik Editores, (Edición original: The Man who mistook his Wife with for a Hut, New York, Summit Books, 1970).

Turner, Mark, (1994) «Design for a Theory of Meaning", en Overton, Willis \& Palermo, David (Eds.): The Nature and Ontogenesis of Meaning, New Jersey, L.E.A.

Xie, Weizhen \& Zhang, Weiwei (2014), «Contributions of cognitive factors in Conceptual Metaphors», Metaphor and Symbol, 29, pp. 171-184. 